Goldschmidt 2021 Abstract

https://doi.org/10.7185/gold2021.5332

\section{First-principles modelling applied to flotation}

\author{
JULIETTE LAINÉ ${ }^{1,2}$, CARLOS VELOSO ${ }^{2}$, ARMANDO \\ CORREA $^{2}$, YANN FOUCAUD ${ }^{3}$ AND MICHAEL BADAWI ${ }^{1}$
}

${ }^{1}$ LPCT - Université de Lorraine

${ }^{2}$ ArcelorMittal Global Research and Development

${ }^{3}$ GeoRessources - Université de Lorraine

Presenting Author: juliette.laine@univ-lorraine.fr

Flotation is the most used mineral separation technique worldwide, processing several billion tonnes of ore per year. This process relies on the selective adsorption of molecules at the mineral/water surface, which will make the mineral surfaces hydrophobic, in case of depressants, or hydrophobic, in case of collectors. Gas bubbles are then injected from the bottom of the cell, diffuse in the cell, attach hydrophobic particles, and carry them in the froth phase, located at the top of the cell. Considering the continuous increase of the ores complexness and decrease of ores grade, thoroughly understanding the molecular mechanisms involved in the flotation is of paramount interest.

Molecular modelling techniques such as Density Functional Theory, eventually combined with molecular dynamics tools ( $A b$ initio Molecular Dynamics), are among the most powerful tools used in material sciences for different applications such as catalysis or depollution [1,2]. They recently have received a new application in the flotation field, with an increasing number of publications dealing with the topic each year [3] (Fig. 1).

These tools provide crucial information on the adsorption mechanisms of flotation reagents, key step in the flotation process. They give access to a molecular-level description that is very difficult to attain by means of sole experimental techniques. For instance, a recent study combining these tools and infrared spectroscopy allowed unravelling the controversial adsorption mechanisms of fatty acids on calcium minerals [4]. Similar works are being conducted on other interest minerals such as magnetite and kaolinite. This aims at increasing the general knowledge about the adsorption mechanisms, but also at finely tuning the reagent amounts, or at developing new reagent formulations [5].

Overall, these tools allow proposing practical and industrial solutions to improve the flotation process, which will undoubtedly help the mining industry to face the growing challenge of grade decrease and complexness increase in ores.

[1] Hounfodji et al. (2021), Chem. Eng. J. 407,127176.

[2] Gueddida et al. (2020), J. Phys. Chem. C.,

[3] Foucaud et al. (2019), Min. Eng., 143, 106020.

[4] Foucaud et al. (2021), J. Colloid Interf. Sci. 583, 692-706.

[5] Foucaud et al. (2019), Chem. Sci. 10, 9928-9940.

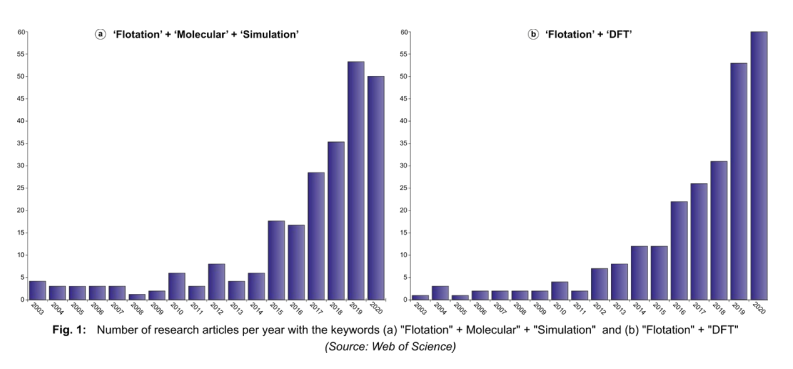

